\title{
UMA ANÁLISE DA JURISPRUDÊNCIA DO TRIBUNAL DE JUSTIÇA DO ESTADO DO RIO GRANDE DO SUL QUANTO À RESPONSABILIDADE CIVIL DAS CONCESSIONÁRIAS DE ESTACIONAMENTO ROTATIVO FRENTE AO FURTO DE VEÍCULOS
}

\author{
JOSÉ EDUARDO TELES SANTOS ${ }^{1}$
}

\section{Resumo:}

O presente estudo presta-se a analisar qual a orientação jurisprudencial do Tribunal de Justiça do estado do Rio Grande do Sul frente litígios que envolvem a responsabilização cível das concessionárias de estacionamento rotativo de vias públicas frente ao furto de veículos. É notório que a crescente frota de veículos nas médias e grandes cidades brasileiras levou às municipalidades a implementação dos estacionamentos rotativos e a delegação de sua administração para empresas concessionárias. Em regra, o usuário estaciona seu veículo mediante remuneração e pode usufruir da vaga por determinado período de tempo. Porém, quando furtados veículos que estão em vagas sob a administração das concessionárias, não tem havido qualquer responsabilização às mesmas. A justiça gaúcha quando acionada pelos usuários tem decidido que as concessionárias de estacionamento rotativo são uma longa manus do município, apenas aplicando o poder de polícia administrativa para limitar o uso da vaga. Por outro lado, os usuários buscam ressarcimento, visto que uma vez tendo remunerado a atividade entendem ser dever das concessionárias a guarda e vigilância dos veículos, acreditando que há, de fato, relação de consumo. Diante desse impasse tem-se a nebulosa situação jurídica que ensejou a reflexão do tema à luz da doutrina e das normas pertinentes.

Palavras-chave: Estacionamento rotativo; responsabilidade civil; relação de consumo; poder de polícia.

1 Acadêmico da Faculdade de Direito da Universidade Federal de Pelotas - UFPEL; Membro do Grupo de Estudos e Pesquisa em Direito do Consumidor - GECON 


\title{
Revista Eletrônica da Faculdade de Direito da Universidade Federal de Pelotas (UFPel) Dossiê Consumo e Vulnerabilidade: a proteção jurídica dos consumidores no século XXI. Vol. 03, N. 1, Jan-Jun., 2017.
}

ISSN - 2448-3303

\begin{abstract}
:
This study intends make analysis what is the jurisprudential guidance of Rio Grande do Sul court when need to judge lawsuit about civil responsibility of thoroughfares parking meter companies front of vehicles theft. It's notorious that crescent vehicles fleet in the brazilian medium and big cities induced the townships a implementation of parking meter and the transference of your management for private companies. Usually, the users park your vehicle by pay and can enjoy for restricted time. But, when the vehicles is in places under parking meter companies management's to theft, isn't answerable. The gaucha's court when call for users it has decided that parking meter companies are administration city's longa manus, only applying the administrative policing power for to limit space use. However, the users want repayment, because the activity is paid, they understand be duty of companies the guard and surveillance of vehicles, believe exist consumer relationship. In front this impasse exist nebula legal situation that cause the reflection of this topic in light of doctrine and relevant laws
\end{abstract}

Key-words: Parking meter; civil responsibility; consumer relationship; administrative policing power.

Sumário: 1. Introdução - 2. A jurisprudência do Tribunal de Justiça do Rio Grande do Sul 3. Análise dos julgados - 3.1 A natureza jurídica dos estacionamentos rotativos -3.2 . Poder de polícia ou serviço público? - 3.3. Reflexões acerca da remuneração da atividade -3.4 . Relação de consumo e responsabilidade civil das concessionárias de estacionamento rotativo. - 4. Considerações Finais - 5. Referências Bibliográficas.

\section{1) Introdução}

As grandes e médias cidades brasileiras estão, cada vez mais, deparando-se com o aumento da frota de veículos particulares, com a necessidade de se reorganizar e controlar de maneira mais adequada o espaço urbano.

A imensa frota demanda condições não apenas de mobilidade, mas também, de vagas disponíveis para estacionamento. Todavia, os municípios brasileiros, deficitários do ponto de vista 


\section{Revista Eletrônica da Faculdade de Direito da Universidade Federal de Pelotas (UFPel) Dossiê Consumo e Vulnerabilidade: a proteção jurídica dos consumidores no século XXI. Vol. 03, N. 1, Jan-Jun., 2017.}

ISSN - 2448-3303

financeiro, encontram alternativa nas concessões para solucionar os problemas com a falta de espaços para estacionamento nas vias públicas.

O aumento da atuação destas empresas concessionárias passou a gerar debate no que cerne a natureza jurídica de sua atividade, bem como os reflexos que dela possam surgir. Essa discussão torna-se mui oportuna dada à incidência dos vários riscos que os usuários estão expostos ao estacionarem seus veículos na via pública, dentre eles, o furto.

O Tribunal de Justiça do estado do Rio Grande do Sul tem entendimento pacífico de que a atividade exercida pelas concessionárias de estacionamento rotativo é apenas o controle das vagas disponíveis dos logradouros públicos servindo como longa manus do município na aplicação do poder de polícia administrativo.

Por outro lado, quando verificada profundamente a questão é possível perceber que a tese de que entre o usuário e a concessionária configura-se relação de consumo (e, portanto, a aplicabilidade da responsabilidade civil nos moldes do Código de Defesa do Consumidor) não parece de todo rechaçável.

Sendo assim, o presente trabalho pretende analisar o entendimento da jurisprudência do Tribunal de Justiça gaúcho quanto a responsabilidade civil das concessionárias de estacionamento rotativo frente o furto de veículos. Neste sentido, foram coletados acórdãos disponíveis no site do Tribunal gaúcho (universo da pesquisa) referentes ao assunto para posterior analise dos principais argumentos suscitados nos julgamentos.

\section{2) A jurisprudência do Tribunal de Justiça do Rio Grande do Sul}

A jurisprudência do Tribunal de Justiça do Rio Grande do Sul quanto à situação específica do furto de veículos estacionados em áreas administradas pelas concessionárias de estacionamento rotativo traz uma série de argumentos que sempre convergem para o entendimento de que a atividade é mero exercício do poder de polícia praticado pelo município de maneira indireta.

Sedimentou-se, portanto, como entendimento jurisprudencial que não assiste razão ao usuário quando este reclama ressarcimento dos danos materiais e morais advindos do fato de seu veículo ter sido furtado quando estava estacionado em alguma das vagas administradas pelas concessionárias de estacionamento rotativo. 


\section{Revista Eletrônica da Faculdade de Direito da Universidade Federal de Pelotas (UFPel) Dossiê Consumo e Vulnerabilidade: a proteção jurídica dos consumidores no século XXI. Vol. 03, N. 1, Jan-Jun., 2017.}

ISSN - 2448-3303

A base de muitas das decisões é a apelação cível $\mathrm{n}^{\circ}$ 595132960, julgada em 06 de dezembro de 1995. No referido acórdão, o relator entendeu pela inaplicabilidade de responsabilização objetiva à administradora do estacionamento rotativo, uma vez que, em função da atividade prestar-se a racionalizar a utilização de um bem de uso comum do povo, tratar-se-ia, portanto, de exercício do poder de polícia e o fato de os funcionários da empresa fiscalizarem se os veículos estacionados estariam respeitando o período de tempo regular não ensejaria a função cumulativa de guarda e vigilância (RIO GRANDE DO SUL, 1995).

Dessa maneira, o argumento principal ainda hoje é justamente afastar a relação de consumo, posto que a atividade exercida pelas concessionárias de estacionamento rotativo não se trataria de um serviço, alegando-se que é exercício do poder de polícia, como é possível depreender deste trecho do acórdão da apelação cível 71000631051 (RIO GRANDE DO SUL, 2004, p. 3):

\footnotetext{
No mérito, em que pese a revelia, impõe-se a improcedência da ação, porque a exigência de prestação pecuniária para a ocupação de vagas na "área azul" não caracteriza a prestação de serviço público, não havendo dever de guarda e vigilância, mas apenas o de gerenciar o adequado uso dos espaços públicos de estacionamento.
}

Entende o tribunal que o fato de gerenciar o adequado uso das vagas disponíveis não seria condição suficiente para que se exigisse das empresas concessionárias o dever de guarda e vigilância, porque apenas caberia este último se os estacionamentos rotativos fossem reconhecidos como serviço público.

Vale destacar que o tribunal considera que a remuneração paga pelo usuário, ainda que prévia, é apenas para que a administradora suporte os custos da operação. Vejamos o que dispõe a apelação cível 70051349231 (RIO GRANDE DO SUL, 2012, p. 6 - 7) referente a litígio originária da comarca de Rio Grande:

\footnotetext{
Nesse passo, atentando-se ao conteúdo da norma que instituiu a "zona azul", verifica-se que se trata de exercício do poder de polícia administrativa, remunerado mediante o pagamento de taxa, verdadeira limitação imposta aos administrados com o objetivo de alcançar o bem comum, consistente, na hipótese, em ampliar o número de vagas em locais de grande circulação e veículos.
}

Ainda que o julgador tenha se referido a "taxa" a lei municipal riograndina (Lei $\mathrm{n}$. 5356/99) que instituiu o estacionamento rotativo pago naquele município positivou o termo "preço público" no art. 3, III: 


\section{Revista Eletrônica da Faculdade de Direito da Universidade Federal de Pelotas (UFPel) Dossiê Consumo e Vulnerabilidade: a proteção jurídica dos consumidores no século XXI. Vol. 03, N. 1, Jan-Jun., 2017.}

ISSN - 2448-3303

Art. $3^{\circ}$. No regulamento a esta Lei, o Poder Executivo estabelecerá:

[...]

III - O valor do preço público devido pelo usuário, dele excluído o deficiente físico portador de selo universal de acesso de carros adaptados ao uso exclusivo de paraplégicos;

É evidente que a remuneração da atividade na cidade de Rio Grande não se configura em taxa, mas sim tarifa. E não é mero equívoco do legislador quanto à nomenclatura, mas sim pela natureza de definição de reajustes, feita por meio de decreto pelo Poder Executivo, conforme autorização da própria lei de criação. Basta observar o disposto pelo Decreto n. 10.597/09:

Art. 21 Os valores de estacionamento e/ou utilizarão do estacionamento rotativo pago serão reajustados pelo Prefeito Municipal, conforme a taxa média de inflação no período, devidamente comprovada através de planilha de cálculo a ser apresentada a SMSTT.

Seguindo na avaliação argumentativa com base na legislação municipal, em diversos acórdãos fora mencionado o fato de que a lei municipal isenta expressamente a concessionário e o município de qualquer forma de responsabilidade civil na hipótese de furto ou dano, o que pode, como veremos na sequência do trabalho, macular de inconstitucionalidade a norma local.

Na apelação cível 70004003745 originária da comarca de Caxias do Sul, por exemplo, remeteu-se na fundamentação do acórdão ao seguinte dispositivo da Lei municipal n. 4803/98:

Art. 13. A exigência de preço para estacionamento de veículos importa tão-somente em autorização de permanência pelo período determinado nesta Lei, não acarretando, ao município ou a permissionária/concessionária do serviço, a obrigação de guarda-los ou vigia-los, nem responsabilidade por acidentes, furtos, roubos ou danos de qualquer espécie, que estes ou seus usuários vierem a sofrer.

Dispositivos normativos de mesmo conteúdo também podem ser encontrados nas demais legislações municipais pesquisadas (Porto Alegre ${ }^{2}$, Canoas $^{3}$ e Guaíba ${ }^{4}$ ).

Oportuno também destacar a apelação cível 70036483592 (RIO GRANDE DO SUL, 2010) onde o voto do desembargador relator destoou do mantra geral emanado pelo tribunal. Mesmo que tenha sido o município a parte demanda e não a concessionária, ainda assim vale a análise.

Trouxe o eminente julgador argumentos que caminham em direção ao entendimento de responsabilizar a municipalidade frente o furto do veículo estacionado em área rotativa. Buscando

2 Lei n. 10.260/07 regulamentada pelo Decreto n. 18.313/13, Art. 13.

3 Lei n. 5.504/10, Art. 15.

4 Lei n. 1969/05, Art. $9^{\circ}$ 


\section{Revista Eletrônica da Faculdade de Direito da Universidade Federal de Pelotas (UFPel) Dossiê Consumo e Vulnerabilidade: a proteção jurídica dos consumidores no século XXI. Vol. 03, N. 1, Jan-Jun., 2017.}

ISSN - 2448-3303

afastar a tese de exercício do poder de polícia, o julgador (RIO GRANDE DO SUL, 2010, p. 3) argumentou:

Tenho que se efetivamente a finalidade da denominada "área azul" fosse unicamente disciplinar o uso de bem comum do povo (estacionamento de veículos nas ruas e avenidas), não haveria razão para o cidadão efetuar pagamento para o uso; bastaria que ele retirasse o ticket para permissão de estacionamento e, caso não cumprisse as regras determinadas, sofreria alguma sanção pelo descumprimento.

Este argumento encontra guarida, por exemplo, no entendimento de Hely Lopes Meireles, como veremos a seguir. Ora, ideal seria que os impostos cobrissem a operação e, somente em caso de desrespeito a regra (como, por exemplo, extrapolar-se o limite máximo de tempo), aplicar-se-ia o poder de polícia com seu caráter sancionador.

Segue o relator (RIO GRANDE DO SUL, 2010, p. 4):

Porém, repito, os munícipes pagam para guardar seus carros em áreas como esta e, a partir do momento em que depositado o veículo no local e efetuado o pagamento do ticket, equipara-se este local com os estabelecimentos privados de estacionamentos. Porque terse-ia entendimento diferenciado entre um espaço privado (v.g. supermercados, shopping centers, etc.) e um espaço publico. Somente para proteção (entre tantas outras hipóteses) do contexto público, em detrimento do cidadão. Lógico que tal não pode obter guarida judicializada.

Ou seja, isso quer dizer que existe entre o cidadão que compra o ticket da "zona azul" e o Município relação contratual ou obrigacional. Aliás, a empresa pública que organiza e fiscaliza o uso destes estacionamentos presta serviços a fim de garantir a rotatividade e, deve, principalmente garantir também a segurança.

Reconheceu o julgador que se configura relação contratual entre o município (no caso também poderia ser a concessionária) e o usuário, desde o momento em que paga-se pelo ticket (compreendido como "uso do serviço"). Esse ponto é importante, dado que em diversas teses defensivas, como na apelação cível 70011022589 (RIO GRANDE DO SUL, 2005, p. 3) o município de Porto Alegre alegou que "o ticket apresentado pelo autor não identificava a placa do veículo, motivo pelo qual não foi demonstrada qualquer relação com o automóvel do autor".

Ora, se adotarmos o entendimento do voto em comento, veremos que da relação contratual subentende-se relação de consumo e, com isso, inversão do ônus da prova prevista pelo art. $6^{\circ}$ inciso VIII do Código de Defesa do Consumidor, cabendo ao município comprovar a ausência do dever de indenizar e não ao autor comprovar a existência do mesmo.

Por fim, o voto do relator restou vencido. 


\section{Revista Eletrônica da Faculdade de Direito da Universidade Federal de Pelotas (UFPel) Dossiê Consumo e Vulnerabilidade: a proteção jurídica dos consumidores no século XXI. Vol. 03, N. 1, Jan-Jun., 2017.}

ISSN - 2448-3303

Diante das informações coletadas junto ao sítio digital da corte gaúcha, tem-se que a atividade exercida pelas concessionárias de estacionamento rotativo é mera aplicação do poder de polícia do município por meio de delegação e, dessa forma, inaplicável qualquer responsabilização nos casos onde ocorrem furtos. Entretanto, realmente prosperam as teses argumentativas das decisões do Tribunal de Justiça do Rio Grande do Sul? Vejamos a seguir.

\section{3) Análise dos julgados}

\section{1) A natureza jurídica dos estacionamentos rotativos}

A ideia de rotatividade nas vagas disponíveis em vias públicas nasceu na cidade norteamericana de Oklahoma City em 1935. A criação deveu-se a Carl C. Magee que já naquela época percebeu a dificuldade que o aumento na frota gerava frente à escassez de vagas de estacionamento no centro da cidade. Dessa forma, ele teve a ideia de instalar máquinas que regulassem o tempo utilizado conforme uma contraprestação em dinheiro ${ }^{5}$. Já naquele momento, surgiu uma polêmica sobre a legalidade da medida adotada, uma vez que inicialmente a população compreendeu a cobrança como mais uma forma de taxação.

No Brasil, os primeiros parquímetros chegaram na década de 1970, na cidade de São Paulo, o maior aglomerado urbano do país. Porém, após alguns testes, e alguns problemas políticos, somente em 1986 é que foram instalados e passaram a ser operacionalizados os parquímetros da capital paulista ${ }^{6}$.

O conceito básico do estacionamento rotativo público é simples: uma atividade que visa limitar a utilização de vagas de estacionamento, de uma determinada região do perímetro urbano, em regra o centro da cidade, a fim de gerar maior rotatividade de veículos estacionados, mediante remuneração, normalmente prévia.

Legislar quanto ao regramento e ao modus operandi dos estacionamentos rotativos é atribuição do poder público municipal. A Constituição de 1988 dispõe em seu Art. 30, I:

\footnotetext{
5 Disponível em: http://www.history.com/this-day-in-history/worlds-first-parking-meter-installed. Acesso em set. 2016. (tradução livre)
}

6Parquímetros nas ruas de SP, uma discussão antiga. Fonte: http://acervo.estadao.com.br/noticias/acervo,parquimetrosnas-ruas-de-sp-uma-discussao-antiga, 11547,0.htm 


\section{Revista Eletrônica da Faculdade de Direito da Universidade Federal de Pelotas (UFPel) Dossiê Consumo e Vulnerabilidade: a proteção jurídica dos consumidores no século XXI. Vol. 03, N. 1, Jan-Jun., 2017.}

ISSN - 2448-3303

Art. 30. Compete aos Municípios:

I - legislar sobre assuntos de interesse local;

O interesse local diz respeito as necessidades específicas da localidade, isto é, as situações exclusivas do lugar que gerem predominante interesse da municipalidade em legislar (LENZA apud TEMER, 2012, p. 448).

O Código de Trânsito Brasileiro por sua vez, legisla especificamente sobre a competência para organização e operacionalização do estacionamento rotativo. Diz o Art. 24, X da referida norma:

Art. 24. Compete aos órgãos e entidades executivos de trânsito dos Municípios, no âmbito de sua circunscrição:

$[\ldots]$

$\mathrm{X}$ - implantar, manter e operar sistema de estacionamento rotativo pago nas vias;

A norma delega aos municípios a competência para que regulem o sistema de estacionamento rotativo. Diante disso, os municípios que enfrentam a escassez de vagas em suas principais áreas de perímetro urbano resolveram delegar a administração para a iniciativa privada por meio de concessões.

\section{2) Poder de polícia ou serviço público?}

O Estado, como se sabe, utiliza de algumas ferramentas para que possa conduzir a vida em sociedade de maneira harmônica e pacífica. Dessa forma, por meio da administração pública, ele utiliza mecanismo que convergem no sentido de primar pelo interesse social em detrimento de interesses individuais sempre, é claro, respeitando a legalidade e os direitos fundamentais.

Assim sendo, limitar o uso de vagas em logradouros públicos seria uma forma com a qual a municipalidade restringiria a liberdade de um indivíduo de utilizar o local para poder oferecer o mesmo ao restante da coletividade, como argumenta o entendimento pacificado pelo Tribunal de Justiça do Rio Grande do Sul.

Uma das ferramentas capaz de restringir a referida liberdade é o chamado poder de polícia administrativo. Hely Lopes Meirelles (2012, p. 139) conceitua poder de polícia como "a faculdade de que dispõe a Administração Pública para condicionar e restringir o uso e gozo de bens, atividades e direitos individuais em benefício da coletividade ou do próprio Estado". 


\section{Revista Eletrônica da Faculdade de Direito da Universidade Federal de Pelotas (UFPel) Dossiê Consumo e Vulnerabilidade: a proteção jurídica dos consumidores no século XXI. Vol. 03, N. 1, Jan-Jun., 2017.}

ISSN - 2448-3303

Na legislação, encontramos a definição de poder de polícia no Código Tributário Nacional, em seu art. 78:

Art. 78. Considera-se poder de polícia atividade da administração pública que, limitando ou disciplinando direito, interesse ou liberdade, regula a prática de ato ou abstenção de fato, em razão de interesse público concernente à segurança, à higiene, à ordem, aos costumes, à disciplina da produção e do mercado, ao exercício de atividades econômicas dependentes de concessão ou autorização do Poder Público, à tranquilidade pública ou ao respeito à propriedade e aos direitos individuais ou coletivos.

Parágrafo único. Considera-se regular o exercício do poder de polícia quando desempenhado pelo órgão competente nos limites da lei aplicável, com observância do processo legal e, tratando-se de atividade que a lei tenha como discricionária, sem abuso ou desvio de poder.

A finalidade é garantir a supremacia do interesse público em detrimento do exercício individual de algum direito, inclusive, direito fundamental (MEIRELLES, 2012, p. 141).

Entretanto, como já mencionado, os municípios não tendo condições de executar a atividade necessariamente delegam para particulares a organização dos estacionamentos rotativos e a consequente cobrança. Assim, nasce a indagação: Sendo o estacionamento rotativo exercício de poder de polícia, poderia ele ser delegado para particulares?

O poder de polícia, em função de seu caráter de imperium, a priori, não parece ser passível de delegação do seu exercício para particulares. Vários são os argumentos para defesa dessa ideia. Flávio Henrique Unes Pereira (2013, p. 83 - 85) em sua obra destacou três principais pontos: (a) ausência de previsão legal; (b) a inconstitucionalidade do exercício do poder de polícia e a autoexecutoriedade pelo particular e (c) a necessidade da pratica do ato por agente público.

Por outro lado, o mesmo autor nos traz a reflexão sobre a possibilidade de delegação do poder de polícia para particulares atuarem em nome do Estado, afastando a ideia de inconstitucionalidade, visto que não há vedação expressa na norma constitucional.

Porém, oportuno observar a possibilidade de as concessionárias de estacionamento rotativo estarem, na verdade, prestando serviço público e, assim, afastar-se a ideia do exercício do poder de polícia.

Os serviços públicos são, segundo Di Pietro (2011, p. 103):

Toda atividade material que a lei atribui ao Estado para que a exerça diretamente ou por meio de seus delegados, como o objetivo de satisfazer concretamente às necessidades coletivas, sob regime jurídico total ou parcialmente público. 


\section{Revista Eletrônica da Faculdade de Direito da Universidade Federal de Pelotas (UFPel) Dossiê Consumo e Vulnerabilidade: a proteção jurídica dos consumidores no século XXI. Vol. 03, N. 1, Jan-Jun., 2017.}

ISSN - 2448-3303

Diante deste aspecto, somando a contraprestação monetária (em regra prévia), seria possível analisar o estacionamento rotativo como um serviço público? Reflitamos.

Existem várias classificações para as espécies de serviços públicos. Quanto a essencialidade, podemos perceber que pela natureza dos estacionamento rotativos eles seriam espécie de serviço de utilidade pública, que são aqueles prestados em função da conveniência percebida pela Administração e com o intuito de facilitar a vida do indivíduo na coletividade (MEIRELLES, 2012, p. 380).

Ora, oferecer vagas de estacionamento em pontos centrais de aglomerados urbanos, garantindo ao usuário a possibilidade deixar seu veículo estacionado próximo ao lugar de destino é oferecer comodidade.

No que cerne a figura do destinatário do serviço, o estacionamento rotativo está próximo dos chamados serviços uti singuli. Esta espécie diz respeito àqueles serviços que são cobrados de usuários imediatos e identificáveis. São os que a norma tributária (CTN, art. 79) se refere.

Ainda que a rua, bem de uso comum do povo, não possa ser individualizada em unidade autônoma (como no caso do fornecimento de energia elétrica que tem medidor individual, por exemplo) as vagas de estacionamento disponíveis podem sim serem mensuradas e individualizadas.

Ante as peculiaridades do estacionamento rotativo e se sua natureza jurídica trata de exercício do poder de polícia ou de prestação de serviço público, oportuno analisar a remuneração da atividade para aprofundar o tema.

\section{3) Reflexões acerca da remuneração da atividade}

A remuneração das concessionárias de estacionamento rotativo, em regra, é por meio do pagamento do ticket para utilização da vaga pelo período de tempo que o usuário necessitar. Ressalta-se que, se observado da ótica de poder de polícia, o valor pago pelo usuário deveria ser taxa, uma vez que este tributo é a remuneração devida, conforme dispõe o Código Tributário Nacional em seu art. 77 dispõe:

Art. 77. As taxas cobradas pela União, pelos Estados, pelo Distrito Federal ou pelos Municípios, no âmbito de suas respectivas atribuições, têm como fato gerador o exercício regular do poder de polícia, ou a utilização, efetiva ou potencial, de serviço público específico e divisível, prestado ao contribuinte ou posto à sua disposição. 


\section{Revista Eletrônica da Faculdade de Direito da Universidade Federal de Pelotas (UFPel) Dossiê Consumo e Vulnerabilidade: a proteção jurídica dos consumidores no século XXI. Vol. 03, N. 1, Jan-Jun., 2017.}

ISSN - 2448-3303

A norma disciplina que o poder de polícia é fato gerador das taxas. As taxas são uma espécie tributária, prevista como tal na Constituição Federal (Art. 145, II) e no Código Tributário Nacional (Art. $5^{\circ}$ ), são aplicáveis ao contribuinte em função do exercício do poder de polícia, diferentemente das tarifas, aplicáveis ao usuário de um determinado serviço (como veremos logo a diante).

Segundo Oliveira apud Ataliba (1993, p. 42) trata-se de "tributo vinculado cuja hipótese de incidência consiste numa atuação estatal direta e imediata referida ao obrigado".

A lei (Código Tributário Nacional) também afirma que a taxa é aplicável aos chamados "serviços públicos específicos e divisíveis" em função de sua potencial ou efetiva fruição por parte dos usuários.

Todavia, frente os julgados analisados e conforme as legislações municipais envolvidas nos litígios percebeu-se a insistência do legislador municipal em determinar as tarifas como forma de remunerar a atividade.

Sendo assim, se a atividade é unicamente exercício do poder de polícia não seria possível cobrança de tarifa, mas sim de taxa. Ainda que se entendesse ser o estacionamento rotativo um serviço público que se encaixa nas definições legais positivadas pelo $\mathrm{CTN}$, merece análise a doutrina deixada por Hely Lopes Meirelles quanto a este assunto.

Em primeiro ponto, as taxas diferenciam-se das tarifas (ou ainda "preços públicos") por estas não são tributos, tem caráter facultativo, isto é, apenas aplicáveis aos usuários do serviço e podem ser modificadas por decretos (MEIRELLES, 2006, p. 162). Além disso, existiria uma diferença quanto a utilidade do serviço remunerado. Hely Lopes Meirelles (2006, p.163) esclarece:

\footnotetext{
Presta-se a tarifa a remunerar os serviços pró-cidadãos, isto é, aqueles que visam dar comodidade aos usuários ou a satisfazê-los em suas necessidades pessoais (telefone, energia elétrica, transporte, etc); ao passo que a taxa é adequada para custeio dos serviços pró-comunidade, ou seja, aqueles que se destinam a atender a exigências específicas da coletividade (água potável, esgoto, segurança pública, etc) [...]
}

Sendo assim, parece razoável entendimento de que para os serviços de utilidade pública $u t i$ singuli seja determinada remuneração mediante tarifa, posto que não cabe onerar ninguém além do usuário, uma vez que somente ele busca utilizar daquele serviço.

Necessário ressaltar a considerável diferença legislativa na fixação dos valores referentes a taxa e a tarifa (preço público). Enquanto esta pode ser instituída e ajustada por ato do executivo, a 


\title{
Revista Eletrônica da Faculdade de Direito da Universidade Federal de Pelotas (UFPel) Dossiê Consumo e Vulnerabilidade: a proteção jurídica dos consumidores no século XXI. Vol. 03, N. 1, Jan-Jun., 2017.
}

ISSN - 2448-3303

aquela depende de lei que a institua e, posteriormente, modifique sua alíquota. Quanto ao assunto, diz Hely Lopes Meirelles (2006, p. 160):

\begin{abstract}
As taxas, como espécie do gênero tributo, só podem ser criadas e aumentadas por lei (CF, art. 150, I) e arrecadadas se a lei que as houver criado ou aumentado estiver em vigor antes do início do exercício financeiro em que devam ser recolhidas (CF, art. 150, III, "b"), e somente pode ser cobradas noventa dias após a publicação dessa lei (CF, art. 150, III, "c"). Ainda nesse ponto diferem dos preços públicos (tarifas), que, não estando sujeitas a essas exigências, são fixadas e alteradas por decreto do executivo, inclusive dentro do mesmo exercício financeiro.
\end{abstract}

Fica evidente que a morosidade legislativa para criação e modificação da taxa frente a agilidade para implementação da tarifa demonstra ser a primeira mais "importante" por ser de natureza tributária, enquanto a segunda, em regra, trata de contra prestação de cunho contratual.

Dessa forma, uma vez que em todos os casos analisados a remuneração das empresas concessionárias de estacionamento rotativo é feita mediante pagamento de tarifa, em que pese a argumentação dos eméritos desembargadores gaúchos, é precipitado descartar-se de plano que não se trata realmente de prestação de serviço público. Nesta senda, aceitando os estacionamentos rotativos como serviço público fornecido através de empresa concessionária, caberia aplicação do Código de Defesa do Consumidor para regular a relação para com o usuário.

Relação de consumo e responsabilidade civil das concessionárias de estacionamento rotativo

$A b$ initio, sabe-se que três são os elementos fundamentais para configuração da relação de consumo: o consumidor, o fornecedor e o serviço (ou produto).

O Código de Defesa do Consumidor dispõe em seu art. $2^{\circ}$ :

Art. $2^{\circ}$ Consumidor é toda pessoa física ou jurídica que adquire ou utiliza produto ou serviço como destinatário final.

Parágrafo único. Equipara-se a consumidor a coletividade de pessoas, ainda que indetermináveis, que haja intervindo nas relações de consumo.

O legislador brasileiro pretendeu dar a norma um conceito de consumidor eminentemente econômico. Analisando a norma, Filomeno (2004, p. 31) constatou: 


\title{
Revista Eletrônica da Faculdade de Direito da Universidade Federal de Pelotas (UFPel) Dossiê Consumo e Vulnerabilidade: a proteção jurídica dos consumidores no século XXI. Vol. 03, N. 1, Jan-Jun., 2017.
}

ISSN - 2448-3303

\begin{abstract}
Abstraídas todas as conotações de ordem filosófica, psicológica e outras, entendemos por "consumidor" qualquer pessoa física ou jurídica que isolada ou coletivamente, contrate para consumo final, em benefício próprio ou de outrem, a aquisição ou a locação de bens, bem como a prestação de um serviço.
\end{abstract}

Um elemento importante trazido tanto pela norma quanto pelo conceito apresentado pelo doutrinador é a expressão "destinatário e consumo final". Essa expressão existe em função de nossa legislação pátria ter filiado-se a chamada teoria finalista (ou subjetiva). Conforme lição de Claudia Lima Marques (2010, p. 85):

\begin{abstract}
Destinatário final seria aquele destinatário fático e econômico do bem ou serviço, seja ele pessoa jurídica ou física. Logo, segundo essa interpretação teleológica, não basta ser destinatário fático do produto, retirá-lo da cadeia de produção, levá-lo para o escritório ou residência - é necessário ser destinatário econômico do bem, não adquiri-lo para revenda, não adquiri-lo para uso profissional, pois o bem seria novamente um instrumento de produção, cujo preço será incluído no preço final do profissional para adquiri-lo. Nesse caso, não haveria exigida 'destinação final' do produto ou do serviço, ou, como afirma o STJ, haveria consumo intermediário, ainda dentro das cadeias de produção e de distribuição. Essa interpretação restringe a figura do consumidor àquele que adquire (utiliza) um produto para uso próprio e de sua família, consumidor seria o não profissional, pois o fim do CDC é tutelar de maneira especial um grupo da sociedade que é mais vulnerável.
\end{abstract}

O ponto chave a ser observado pelo jurista no momento de identificação da relação de consumo é a vulnerabilidade de uma das partes.

A vulnerabilidade é, pois, elemento essencial a ser verificado na relação de consumo. Lima Lopes (1992, p. 78) ressaltou que "um elemento essencial, que no fundo é o que justifica a existência da própria disciplina da relação de consumo: a subordinação econômica do consumidor".

Em suma, considera-se consumidor a pessoa física ou jurídica, que utilizar produtos ou serviços como destinatário final, comprovando sua vulnerabilidade frente o fornecedor, no mercado.

O fornecedor, por sua vez, está definido no Art. $3^{\circ}$ do CDC:

Art. $3^{\circ}$ Fornecedor é toda pessoa física ou jurídica, pública ou privada, nacional ou estrangeira, bem como os entes despersonalizados, que desenvolvem atividade de produção, montagem, criação, construção, transformação, importação, exportação, distribuição ou comercialização de produtos ou prestação de serviços.

O fornecedor é a figura que tem por atividade oferecer no mercado de consumo bens ou serviços mediante remuneração. Pode ser tanto pessoa física (e aqui temos, por exemplo, os 


\section{Revista Eletrônica da Faculdade de Direito da Universidade Federal de Pelotas (UFPel) Dossiê Consumo e Vulnerabilidade: a proteção jurídica dos consumidores no século XXI. Vol. 03, N. 1, Jan-Jun., 2017.}

ISSN - 2448-3303

empresários individuais e profissionais liberais) ou jurídica, sendo esta última a mais comum como fornecedora.

José Geraldo Brito Filomeno (2004, p. 43) muito bem resume o fornecedor:

Tem-se, por conseguinte, que fornecedor é qualquer pessoa física, ou seja, qualquer um que, a título singular, mediante desempenho de atividade mercantil ou civil e de forma habitual, ofereça no mercado produtos ou serviços, e a jurídica, da mesma forma, mas em associação mercantil ou civil e de forma habitual.

Percebe-se, pois, que alguns elementos como "habitualidade", e a "produção ou fornecimento em massa" são essenciais para observar-se a figura do fornecedor na relação de consumo. E, além disso, a questão da remuneração também importa. Para Bruno Miragem (2013, p. 156) "desta forma, incide as regras do CDC à prestação de serviço somente se este for remunerado, indicando a atividade econômica no fornecimento de serviços para caracterizá-lo fornecedor".

Quanto aos serviços, dispõe o Art. $3^{\circ}, \S 2^{\circ}$ :

Art. $3^{\circ}[\ldots]$

$\S 2^{\circ}$ Serviço é qualquer atividade fornecida no mercado de consumo, mediante remuneração, inclusive as de natureza bancária, financeira, de crédito e securitária, salvo as decorrentes das relações de caráter trabalhista.

A definição legal ressalta, sobretudo, o termo "qualquer". Rizzatto Nunes (2005 p. 95) diz que "serviço é qualquer atividade fornecida ou, melhor dizendo, prestada no mercado de consumo". Seja um mero corte de cabelo ou o fornecimento de energia elétrica, teremos uma atividade considera como serviço, a luz do CDC.

É preciso atentar-se para a ideia que a norma traz de associação entre "serviço" e "atividade". Isto importa, pois os serviços, entendidos como atividade, são, basicamente, um conjunto de atos que convergem em direção a uma finalidade específica (NUNES, 2005, p. 96).

Por fim, como o próprio CDC prevê, o Estado pode de forma direta ou por meio de concessionárias e permissionárias prestar serviços para a população. Sendo assim, passa-se agora a análise da relação de consumo nestas hipóteses.

Ainda que os serviços públicos sigam, em regra, a norma de direito público incide sobre eles, em determinadas situações e em função de sua natureza, regras de direito privado, dentre elas, o CDC (MELLO e FILHO apud DI PIETRO, 2011, p. 104). 


\section{Revista Eletrônica da Faculdade de Direito da Universidade Federal de Pelotas (UFPel) Dossiê Consumo e Vulnerabilidade: a proteção jurídica dos consumidores no século XXI. Vol. 03, N. 1, Jan-Jun., 2017.}

ISSN - 2448-3303

Além disso, a própria Constituição previu a necessidade de uma legislação de regrasse os direitos dos usuários de serviços públicos. Preenchendo a exigência constitucional, promulgou-se a Lei n. 8987/95 que dispõe sobre o regime de concessão e permissão da prestação de serviços públicos.

O referido diploma legal introduziu alguns pontos que complementam a utilização do $\mathrm{CDC}$, sobretudo quando trata as características que os serviços devem ter e os direitos que o usuário possui.

Diz o art. $6^{\circ}$ e seu $\S 1^{\circ}$ da norma em destaque:

Art. 6o Toda concessão ou permissão pressupõe a prestação de serviço adequado ao pleno atendimento dos usuários, conforme estabelecido nesta Lei, nas normas pertinentes e no respectivo contrato.

$\S$ 1o Serviço adequado é o que satisfaz as condições de regularidade, continuidade, eficiência, segurança, atualidade, generalidade, cortesia na sua prestação e modicidade das tarifas.

E segue a norma com o art. $7^{\circ}$ :

Art. $7^{\circ}$. Sem prejuízo do disposto na Lei no 8.078, de 11 de setembro de 1990, são direitos e obrigações dos usuários:

I - receber serviço adequado;

II - receber do poder concedente e da concessionária informações para a defesa de interesses individuais ou coletivos;

III - obter e utilizar o serviço, com liberdade de escolha entre vários prestadores de serviços, quando for o caso, observadas as normas do poder concedente. (Redação dada pela Lei $\mathrm{n}^{\circ}$ 9.648, de 1998)

IV - levar ao conhecimento do poder público e da concessionária as irregularidades de que tenham conhecimento, referentes ao serviço prestado;

$\mathrm{V}$ - comunicar às autoridades competentes os atos ilícitos praticados pela concessionária na prestação do serviço;

VI - contribuir para a permanência das boas condições dos bens públicos através dos quais lhes são prestados os serviços.

Pode-se inferir da análise dos dois dispositivos que a norma não exclui a aplicação do CDC, pelo contrário, amplia garantias para o consumidor de serviços públicos.

Assim como diversas outras funções estatais que visam garantir o bem estar da coletividade, o estacionamento rotativo, dado seus aspectos econômicos e operacionais, necessita ser delegado à terceiro. A isto, chama-se concessão.

Nas palavras de Celso Antônio Bandeira de Mello (2006, p. 727): 


\section{Revista Eletrônica da Faculdade de Direito da Universidade Federal de Pelotas (UFPel) Dossiê Consumo e Vulnerabilidade: a proteção jurídica dos consumidores no século XXI. Vol. 03, N. 1, Jan-Jun., 2017.}

ISSN - 2448-3303

Concessão de serviço público é o instituto através do qual o Estado atribui o exercício de um serviço público a alguém que aceita prestá-lo em nome próprio, por sua conta e risco, nas condições fixadas e alteráveis unilateralmente pelo Poder Público, mas sob a garantia contratual de um equilíbrio econômico-financeiro, remunerando-se pela própria exploração do serviço, em geral e basicamente mediante tarifas cobradas diretamente dos usuários do serviço.

A responsabilidade civil das concessionárias seguirá, em regra, o disposto no Art. $37, \S 6^{\circ}$ da Constituição Federal de 1988 que diz

As pessoas jurídicas de direito público e as de direito privado prestadoras de serviços públicos responderão pelos danos que seus agentes, nessa qualidade, causarem a terceiros, assegurado o direito de regresso contra o responsável nos casos de dolo ou culpa.

Trata-se de uma das excepcionalidades no direito brasileiro onde admite-se a responsabilidade civil objetiva. Entretanto, quando dano originar-se da omissão entende-se que é preciso haver prova da culpa (em sentido amplo). É que o Brasil adotou como regra a chamada teoria do risco administrativo. Segundo Hely Lopes Meirelles (2006, p. 144), esse entendimento de aplicação da teoria do risco administrativo evidencia que:

A obrigação de indenizar o membro da coletividade lesado pelo Poder Público deriva única e exclusivamente da injusta lesão, inferida da só ausência de culpa da vítima perante o mesmo Poder Público que tem a precípua missão de preservar seus direitos e seu patrimônio.

Por outro lado, a responsabilidade civil nas relações de consumo tem particularidades muito específicas, sobretudo, pois a legislação consumerista tem por vocação “ajustar a balança do Direito" regulando interações jurídicas entre polos desiguais.

Esta vocação vem estabelecida pelo próprio Art. $1^{\text {o }}$ do Código de Defesa do Consumidor:

Art. $1^{\circ} \mathrm{O}$ presente código estabelece normas de proteção e defesa do consumidor, de ordem pública e interesse social, nos termos dos arts. $5^{\circ}$, inciso XXXII, 170 , inciso V, da Constituição Federal e art. 48 de suas Disposições Transitórias.

O dispositivo vestibular da norma já delineia a sua natureza de proteção do consumidor como elo mais fraco nas relações com as empresas no mercado de consumo.

Além disso, é sabido que no modelo econômico capitalista lançar-se ao mercado implica em uma série de variáveis que podem garantir tanto o sucesso quanto o fracasso. O magistério de Rizzatto Nunes (2005, p. 153) nos diz: 


\section{Revista Eletrônica da Faculdade de Direito da Universidade Federal de Pelotas (UFPel) Dossiê Consumo e Vulnerabilidade: a proteção jurídica dos consumidores no século XXI. Vol. 03, N. 1, Jan-Jun., 2017.}

ISSN - 2448-3303

Uma das principais características da atividade econômica é o risco. Os negócios implicam risco. Na livre iniciativa a ação do empreendedor está aberta simultaneamente ao sucesso e ao fracasso. A boa avaliação dessas possibilidades por parte do empresário é fundamental para o investimento. Um risco mal calculado pode levar o negócio à bancarrota. Mas o risco é dele.

Assim sendo, percebemos que a teoria do risco (ou também "teoria do risco do negócio") surge como base para sustentar a responsabilidade civil objetiva nas relações de consumo. Afirma Almeida (2013, p. 425) que:

Pela teoria do risco da atividade ou do empreendimento, todo aquele que fornece produto ou serviço no mercado de consumo cria um risco de dano aos consumidores e, concretizado este, surge o dever de repará-lo independentemente da comprovação de dolo ou de culpa.

Essa teoria desloca a responsabilidade da ideia de culpa para a questão do risco da atividade desempenhada, isto é, o que ela é capaz de causar. Mais uma vez, o fato de o fornecedor experimentar o bônus e arcar com o ônus, somado ao princípio da confiança legítima, faz com que ele responda de forma objetiva (ALMEIDA, 2013, p. 425).

Dessa forma, uma vez que as empresas concessionárias de estacionamento rotativo experimentam os lucros advindos do pagamento dos usuários caberia também a elas arcarem com os riscos que o negócio possui e, dentre eles, as hipóteses de furto do veículo.

No CDC, a responsabilidade biparte-se no sentido de proteger tanto os fatores pessoais do consumidor (bem estar físico e mental) quanto patrimoniais (possíveis perdas econômicas)

Como a responsabilidade civil é objetiva nas relações de consumo, faz-se necessário a comprovação: (a) defeito ou vício do produto ou serviço (que deve ser afastada mediante prova por parte do fornecedor); (b) evento danoso e (c) nexo de causalidade.

Dispõe o código consumeirista em seu art. 14:

Art. 14. O fornecedor de serviços responde, independentemente da existência de culpa, pela reparação dos danos causados aos consumidores por defeitos relativos à prestação dos serviços, bem como por informações insuficientes ou inadequadas sobre sua fruição e riscos.

$\S 1^{\circ} \mathrm{O}$ serviço é defeituoso quando não fornece a segurança que o consumidor dele pode esperar, levando-se em consideração as circunstâncias relevantes, entre as quais:

I - o modo de seu fornecimento;

II - o resultado e os riscos que razoavelmente dele se esperam;

III - a época em que foi fornecido.

$\S 2^{\circ} \mathrm{O}$ serviço não é considerado defeituoso pela adoção de novas técnicas.

$\S 3^{\circ} \mathrm{O}$ fornecedor de serviços só não será responsabilizado quando provar:

I - que, tendo prestado o serviço, o defeito inexiste; 


\section{Revista Eletrônica da Faculdade de Direito da Universidade Federal de Pelotas (UFPel) Dossiê Consumo e Vulnerabilidade: a proteção jurídica dos consumidores no século XXI. Vol. 03, N. 1, Jan-Jun., 2017.}

ISSN - 2448-3303

II - a culpa exclusiva do consumidor ou de terceiro.

$\S 4^{\circ} \mathrm{A}$ responsabilidade pessoal dos profissionais liberais será apurada mediante a verificação de culpa.

A responsabilidade pelo fato do serviço, dizem Denari et al. (2004, p. 175), “decorre da exteriorização de um vício de qualidade, vale dizer, de um defeito capaz de frustrar a legítima expectativa do consumidor quanto à sua utilização ou fruição". Ora, sempre que algum serviço for prestado de forma que viole o bem estar fisio-psicológico ou gere perda patrimonial ao consumidor teremos a responsabilização do prestador.

Ainda que o legislador tenha utilizado de maneira confusa os termos "consumir" e "usar", sugere a melhor doutrina que entendamos ser o "uso" uma forma especial de "consumo".

Quanto as excludentes da responsabilidade, previstas no art. $14, \S \S 2^{\circ}$ e $3^{\circ}$ do CDC, oportuno pormenorizar aquela que mais adequadamente é aplicável ao estudo em tela, isto é, a comprovação de culpa exclusiva de terceiro.

Além disso, quando se fala em culpa exclusiva da vítima ou de terceiro grife-se o termo “exclusiva". Isto, posto que averiguada a culpa concorrente, ainda assim caberá ao prestador do serviço reparar dano causado pelo defeito (NUNES, p. 302). Segundo, Melo (2010):

\footnotetext{
Neste caso o que o Código prevê é a possibilidade de exclusão de responsabilidade decorrente do uso inadequado de produto seja pelo próprio adquirente, seja por ingerência de terceira pessoa. Mas não é somente o uso inadequado que poderá exonerar o fornecedor do dever de indenizar, pois também poderão ocorrer outras hipóteses, tais como: o consumidor ser negligente ao manusear o produto; não seguir as instruções de uso; entregar para uso a pessoa não recomendada; consumir o produto com validade vencida, dentre outras.
}

Terceiro in casu é qualquer pessoa que não se identifique com os partícipes da relação de consumo descrita no art. 12 e que envolve, de um lado, o fabricante, o produtor, o construtor ou importador e, de outro, o consumidor. Oportuno ressaltar que, ainda que o autor tenha se referido no trecho aos produtos, cabe também a reflexão quanto aos serviços.

Uma das pessoas que poderia ser considera "terceiro" é o criminoso que furta determinado bem. O crime de furto, positivado pelo art. 155 de nosso Código Penal, é um dos crimes contra o patrimônio por excelência tratando de um delito onde há subtração do bem, sem que haja violência ou grave ameaça.

Por outro lado, quando falamos dos estacionamentos rotativos, é plausível inferir-se que a concessionária tem por atividade fim garantir ao veículo espaço para o estacionamento de maneira 


\title{
Revista Eletrônica da Faculdade de Direito da Universidade Federal de Pelotas (UFPel) Dossiê Consumo e Vulnerabilidade: a proteção jurídica dos consumidores no século XXI. Vol. 03, N. 1, Jan-Jun., 2017.
}

ISSN - 2448-3303

similar ao contrato de depósito, mas com natureza de relação de consumo. Dessa forma, o dever de guarda e vigilância estaria inerente a atividade e, assim como no caso de estacionamentos privados, a quebra do referido dever serviria de gatilho para a pretensão indenizatória do usuário.

Interessante refletir que, como bem aponta a súmula 130 do Superior Tribunal de Justiça, é de responsabilidade da empresa qualquer dano ou furto que o veículo do consumidor sofra estando em seu estacionamento ${ }^{7}$.

Oportuno lembrar que mesmo nos estabelecimentos onde o estacionamento é oferecido como "cortesia", cabe o dever de guarda e vigilância as empresas, uma vez que trata-se da chamada vantagem indireta. Flávio Tartuce (2016, p. 93) diz:

\begin{abstract}
Cumpre esclarecer que, apesar de a lei mencionar expressamente a remuneração, dando um caráter oneroso ao negócio, admite-se que o prestador tenha vantagens indiretas, sem que isso prejudique a qualificação da relação consumerista. Como primeiro exemplo, invoca-se o caso do estacionamento gratuito em lojas, shoppings centers, supermercados e afins, respondendo a empresa que é beneficiada pelo serviço, que serve como atrativo aos consumidores.
\end{abstract}

Logo, se empresas que não exploram como atividade-fim o serviço de estacionamento respondem na forma da lei consumeirista caso não cumpram seu dever de guarda e vigilância dos veículos, seria plausível que uma empresa, em que pese concessionária do poder público, mas que explora como atividade-fim o oferecimento de vagas de para estacionamento não deva ressarcir os usuários caso enfrentem o prejuízo de ter seu meio de transporte roubado?

Por fim, as próprias legislações locais, preocupadas justamente com os riscos de furto dos veículos nas áreas de estacionamento rotativo, criaram normas no intuito de isentar tanto o município quanto a empresa concessionária da responsabilidade por quaisquer sinistro, conforme já mencionado neste artigo. Vale ressaltar que tal hipótese prospera apenas porque não se considera o estacionamento rotativo como sendo serviço público. Se assim fosse, a possibilidade de verificar-se a relação de consumo entre usuário e concessionária afastaria a aplicabilidade de normas municipais com esse conteúdo, uma vez que seriam elas inconstitucionais.

A inconstitucionalidade assentar-se-ia no fato de que a norma estaria restringindo direito do consumidor, um direito fundamental garantido pelo próprio Art. 5 $5^{\circ}$ XXXII da Constituição. Gilmar Mendes e Paulo Gonet Branco (2012, p. 190) esclarecem que "no tocante aos direitos e

7 Súmula 130. A empresa responde, perante o cliente, pela reparação de dano ou furto de veiculo ocorridos em seu estacionamento. 


\section{Revista Eletrônica da Faculdade de Direito da Universidade Federal de Pelotas (UFPel) Dossiê Consumo e Vulnerabilidade: a proteção jurídica dos consumidores no século XXI. Vol. 03, N. 1, Jan-Jun., 2017.}

ISSN - 2448-3303

garantias individuais, mudanças que minimizem a sua proteção, ainda que topicamente, não são admissíveis".

Dessa maneira, toda lei municipal, como as averiguadas no presente trabalho, que se propõem a isentar a concessionária de responsabilidade pelo furto do veículo ferem frontalmente a carta magna brasileira, portanto, não merecem aplicação.

\section{4) Considerações Finais}

O presente trabalho propôs-se a analisar a jurisprudência do Tribunal e Justiça do Estado do Rio Grande do Sul, mas sempre utilizando a doutrina e norma como parâmetros de avaliação.

Pode-se observar que é pacífico para o tribunal sul-rio-grandense que a atividade das concessionárias é exercício do poder de polícia, afastando completamente qualquer forma de responsabilidade civil objeta ou, ainda, reconhecimento de relações de consumo.

Há que se ressaltar que a base dos fundamentos de várias das decisões é um julgamento dos anos 1990, ou seja, o Tribunal não procurou revistar o tema frente as novas demandas, preferindo manutenção do entendimento. Vale o destaque de que este "primeiro precedente" não visitou as profundezas da questão.

Dentre os vários argumentos utilizados pelos desembargadores, evidentemente destacaram-se: (a) a finalidade da atividade é meramente democratização do espaço urbano; (b) não está implícito aos fiscais o dever de guarda e vigilância dos veículos; (c) não há serviço público e nem relação contratual.

Apenas em um voto isolado, observou-se posicionamento discordante, tentando construção argumentativa no sentido de atribuir responsabilidade ao poder público. Porém, foi voto vencido.

Diante de todas estas informações, denota-se que o tema é deveras complicadíssimo e também é riquíssimo, posto que há uma interdisciplinaridade dentre as várias cearas do Direito (administrativo, civil, consumidor, constitucional, tributário, etc.).

Em que pese a lógica jurídica aplicada pelos tribunais atualmente (e sim, tem seus fundamentos), parece não razoável rechaçar-se de imediato o entendimento diverso, visto argumentos aqui expostos. O estágio atual das legislações municipais gera justamente a confusão onde tanto julgadores, quanto usuários não conseguem identificar quais direitos e dever aplicáveis. 


\section{Revista Eletrônica da Faculdade de Direito da Universidade Federal de Pelotas (UFPel) Dossiê Consumo e Vulnerabilidade: a proteção jurídica dos consumidores no século XXI. Vol. 03, N. 1, Jan-Jun., 2017.}

ISSN - 2448-3303

Parece-nos que, antes e tudo, a legislação deve tomar um rumo e escolher qual caminho seguir. A manutenção do modelo atual, qual seja, de concessão da exploração da atividade para terceiro e remuneração da mesma por meio de tarifa é mais compatível com a tese de que os estacionamentos rotativos são serviço de utilidade pública e, nessa monta, há relação de consumo entre usuário e concessionária, logo, dever de indenizar no caso de furto do veículo.

Por outro lado, se se busca que essa atividade seja efetivamente poder de polícia seria mais adequado alterações legislativas no sentido de mudar-se a forma de remuneração (taxa ao invés de tarifa), aplicá-la em caráter sancionador e prestar a atividade por meio da administração pública direta.

O Tribunal de Justiça do Rio Grande do Sul, bem como os demais Tribunais, não devem legislar sobre o tema, é claro, sob pena de desapontarem o velho Montesquieu, porém, devem buscar exercitar um raciocínio jurídico mais apurado e aterem-se com maior minúcia aos detalhes que envolvem o tema.

Em suma, é preciso que os operadores do direito debrucem-se sobre o tema, sempre tendo como meta a busca pela verdade a fim de criarem substrato para que os magistrados tenham maiores condições de analisar as demandas.

\section{5) Referências}

ALMEIDA, Fabrício Bolzan de. Direito do consumidor esquematizado. - São Paulo: Saraiva, 2013.

BRASIL. Constituição Federal de 1988. Vade Mecum / org. Nylson PAim de Abreu Filho. 11 ed. - Porto Alegre: Verbo Jurídico, 2015.

Código de Defesa do Consumidor. Vade Mecum / org. Nylson Paim de Abreu Filho. 11 ed. - Porto Alegre: Verbo Jurídico, 2015.

. Código Penal. Vade Mecum / org. Nylson Paim de Abreu Filho. 11 ed. - Porto Alegre: Verbo Jurídico, 2015.

Código de Trânsito Brasileiro. Vade Mecum / org. Nylson Paim de Abreu Filho. 11 ed. Porto Alegre: Verbo Jurídico, 2015.

Código Tributário Nacional. Vade Mecum / org. Nylson Paim de Abreu Filho. 11 ed. Porto Alegre: Verbo Jurídico, 2015.

Lei n. 8.987 de 13 de fevereiro de 1995. Vade Mecum / org. Nylson Paim de Abreu Filho. 11 ed. - Porto Alegre: Verbo Jurídico, 2015.

Superior Tribunal de Justiça. Súmula 130. Vade Mecum / org. Nylson Paim de Abreu Filho. 11 ed. - Porto Alegre: Verbo Jurídico, 2015.

CANOAS. Lei n. 5.504 de 17 de maio de 2010. Dispões sobre o estacionamento rotativo pago nas vias e logradouros do município de Canoas. Disponível em: 


\section{Revista Eletrônica da Faculdade de Direito da Universidade Federal de Pelotas (UFPel) \\ Dossiê Consumo e Vulnerabilidade: a proteção jurídica dos consumidores no século XXI. Vol. 03, N. 1, Jan-Jun., 2017.}

ISSN - 2448-3303

https://leismunicipais.com.br/a/rs/c/canoas/lei-ordinaria/2010/551/5504/lei-ordinaria-n-55042010-dispoe-sobre-o-estacionamento-rotativo-pago-nas-vias-e-logradouros-do-municipio-decanoas?q=5504. Acesso em: 01 jul. 2016.

CAXIAS DO SUL, Lei n. $\mathbf{4 . 8 0 3}$ de 15 de janeiro de 1998. Autoriza o poder executivo municipal a instituir, nas vias e logradouros públicos, áreas especiais para estacionamento rotativo por tempo delimitado, denominada zona azul, e dá outras providências. Disponível em: https://leismunicipais.com.br/a/rs/c/caxias-do-sul/lei-ordinaria/1998/481/4803/lei-ordinaria-n4803-1998-autoriza-o-poder-executivo-municipal-a-instituir-nas-vias-e-logradouros-publicosareas-especiais-para-estacionamento-por-tempo-delimitado-denominada-zona-azul-e-da-outrasprovidencias?q=4803. Acesso em: 14 ago. 2016.

DENARI, Zelmo et. al. Código de Defesa do Consumidor: comentado pelos autores do anteprojeto / Ada Pellegrini Grinover [et. al.] - 8 ed. - Rio de Janeiro: Forense Universitária, 2004.

DI PIETRO, Maria Sylvia Zanella. Direito administrativo - 24 ed. - São Paulo: Atlas, 2011.

FILOMENO, José Geraldo Brito et. al. Código de Defesa do Consumidor: comentado pelos autores do anteprojeto / Ada Pellegrini Grinover [et. al.] - 8 ed. - Rio de Janeiro: Forense Universitária, 2004.

GUAÍBA, Lei n. 1.969 de 04 de julho de 2005. Fica autorizado o município de Guaíba a implantar, manter e operar sistema de estacionamento rotativo pago e dá outras providências. Disponível em:

https://leismunicipais.com.br/a/rs/g/guaiba/lei-ordinaria/2005/197/1969/lei-ordinaria-n-1969-

2005-fica-autorizado-o-municipio-de-guaiba-a-implantar-manter-e-operar-sistema-de-

estacionamento-rotativo-pago-e-da-outras-providencias?q=1969. Acesso em: 14 jul. 2016.

LENZA, Pedro. Direito constitucional esquematizado - 16. ed. rev., atual. e ampl. - São Paulo : Saraiva, 2012.

LOPES, José Reinaldo de Lima. Responsabilidade civil do fabricante e a defesa do consumidor. São Paulo: Revista dos Tribunais, 1992.

MARQUES, Claudia Lima; BENJAMIN, Antonio Herman V.; BESSA, Leonardo Roscoe. Manual de Direito do Consumidor. 3. ed. São Paulo: RT, 2010.

MEIRELLES, Hely Lopes. Direito Administrativo Brasileiro. 39. ed. atual. São Paulo: Malheiros, 2012.

Direito Municipal Brasileiro. 14. ed. atul. São Paulo: Malheiros: 2006.

MENDES, Gilmar Ferreira; BRANCO, Paulo Gustavo Gonet. Curso de direito constitucional. 7 ed. - São Paulo: Saraiva, 2012.

MELO, Nehemias Domingos de. Responsabilidade civil nas relações de consumo. Revista Âmbito jurídico. $n^{\circ} 83$ Ano XIII. Dez/2010. Disponível em:

http://www.ambitojuridico.com.br/site/?n_link=revista_artigos_leitura\&artigo_id=8475\&revista_ caderno $=10$. Acesso em: 01 set. 2016

MELLO, Celso Antônio Bandeira de. Curso de Direito Administrativo. 26 ed. rev. e atual. São Paulo: Malheiros, 2006.

MIRAGEM, Bruno. Curso de direito do consumidor. $4^{a}$ ed. ver., atual. e ampl. São Paulo: Editora Revista dos Tribunais, 2013

NUNES, Luiz Antonio Rizzato. Curso de direito do consumidor. - 2 ed. rev. modif. E atual. São Paulo: Saraiva, 2005.

OLIVEIRA, Regis Fernandes de. Manual de direito financeiro. - 1 ed. - São Paulo: Revista dos Tribunais, 1993. 


\section{Revista Eletrônica da Faculdade de Direito da Universidade Federal de Pelotas (UFPel) Dossiê Consumo e Vulnerabilidade: a proteção jurídica dos consumidores no século XXI. Vol. 03, N. 1, Jan-Jun., 2017.}

ISSN - 2448-3303

PEREIRA, Flávio Henrique Unes. Regulação, fiscalização e sanção: fundamentos e requisitos da delegação do exercício do poder de polícia administrativa a particulares. - Belo Horizonte: Fórum, 2013.

PORTO ALEGRE. Lei n. 10.260 de 28 de setembro de 2007. Rege o estacionamento temporário de veículos, mediante pagamento em vias e logradouros públicos de uso comum. Disponível em: https://leismunicipais.com.br/a/rs/p/porto-alegre/lei-ordinaria/2007/1026/10260/lei-ordinaria-n10260-2007-rege-o-estacionamento-temporario-de-veiculos-mediante-pagamento-em-vias-elogradouros-publicos-de-uso-comum-revoga-as-leis-ns-6002-de-2-de-dezembro-de-1987-6806de-21-de-janeiro-de-1991-7775-de-27-de-marco-de-1996-7919-de-16-de-dezembro-de-19968895-de-24-de-abril-de-2002-8897-de-30-de-abril-de-2002-e-9418-de-6-de-abril-de-2004-elibera-a-criterio-da-secretaria-municipal-dos-transportes-smt-nos-horarios-e-dias-da-semana-quedetermina-os-locais-onde-o-estacionamento-e-proibido?q=10260. Acesso em: 13 ago. 2016.

Decreto n. 18.313 de 10 de junho de 2013. Regulamenta a Lei n. 10.260 de 28 de setembro de 2007 - que rege o estacionamento rotativo temporário de veículos, mediante pagamento, em vias e logradouros públicos de uso comum. Disponível em: https://leismunicipais.com.br/a/rs/p/porto-alegre/decreto/2013/1832/18313/decreto-n-18313-2013regulamenta-a-lei-n-10260-de-28-de-setembro-de-2007-que-rege-o-estacionamento-temporariode-veiculos-mediante-pagamento-em-vias-e-logradouros-publicos-de-uso-comum-revoga-as-leisn-6002-de-2-de-dezembro-de-1987-6806-de-21-de-janeiro-de-1991-7775-de-27-de-marco-de1996-7919-de-16-de-dezembro-de-1996-8895-de-24-de-abril-de-2002-8897-de-30-de-abril-de2002-e-9418-de-6-de-abril-de-2004-e-libera-a-criterio-da-secretaria-municipal-de-transportessmt-nos-horarios-e-dias-da-semana-que-determina-os-locais-onde-o-estacionamento-e-proibidorevogando-os-decretos-n-13183-de-5-de-abril-de-2001-13646-de-25-de-fevereiro-de-2002-15339de-27-de-outubro-de-2006-e-17393-de-19-de-outubro-de-2011?q=18313. Acesso em: 13 ago. 2016.

RIO GRANDE. Lei n. 5356, de 11 de outubro de 1999. Dispõe sobre a criação de áreas especiais de estacionamento de veículos automotores nas vias e logradouros públicos. Disponível em: https://leismunicipais.com.br/a/rs/r/rio-grande/lei-ordinaria/1999/536/5356/lei-ordinaria-n-53561999-dispoe-sobre-a-criacao-de-areas-especiais-de-estacionamento-de-veiculos-automotores-nasvias-e-logradouros-publicos-e-da-outras-providencias?q=estacionamento\%20rotativo. Acesso 04 ago. 2016.

Decreto n. 10.597, de 30 de dezembro de 2009. Dispõe sobre a operacionalidade do sistema de estacionamento rotativo - set, nas vias públicas do município do rio grande e dá outras providências. Disponível em: https://leismunicipais.com.br/a/rs/r/riogrande/decreto/2009/1059/10597/decreto-n-10597-2009-dispoe-sobre-a-operacionalidade-dosistema-de-estacionamento-rotativo-set-nas-vias-publicas-do-municipio-do-rio-grande-e-daoutras-providencias acesso em 04 de ago. 2016.

RIO GRANDE DO SUL, Tribunal de Justiça. Apelação Cível n. 595132960. Des Rel. Tupinambá Miguel Castro do Nascimento. Primeira Câmara Cível. Julgado em: 06/12/1995. Disponível

em: http://www1.tjrs.jus.br/site_php/consulta/consulta_processo.php?nome_comarca=Tribunal+de+Ju sti $\% E 7 a \& v e r s a o=\& v e r s a o \_f o n e t i c a=1 \&$ tipo $=1 \& i d \_c o m a r c a=700 \&$ num_processo_mask=595132 960\&num_processo=595132960\&codEmenta=309795\&temIntTeor=false. Acesso em: 14 ago. 2016

Tribunal de Justiça. Apelação Cível n. 71000631051. Des Rel. Ricardo Torres Hermann.

Primeira Turma Recursal Cível. Julgado em: 31/03/2005. Disponível em: http://www1.tjrs.jus.br/site_php/consulta/consulta_processo.php?nome_comarca=Tribunal+de+Ju 


\section{Revista Eletrônica da Faculdade de Direito da Universidade Federal de Pelotas (UFPel) Dossiê Consumo e Vulnerabilidade: a proteção jurídica dos consumidores no século XXI. Vol. 03, N. 1, Jan-Jun., 2017.}

ISSN - 2448-3303

sti\%E7a\&versao=\&versao_fonetica $=1 \&$ tipo $=1 \& i d \_c o m a r c a=700 \&$ num_processo_mask $=710006$ 31051\&num_processo=71000631051\&codEmenta=1044869\&temIntTeor=true. Acesso em: 12 ago. 2016.

Tribunal de Justiça. Apelação Cível n. 70051349231. Des Rel. Marilene Bonzanin. Nona Câmara Cível. $\quad$ Julgado em: 12/12/2012. Disponível em:http://www1.tjrs.jus.br/site_php/consulta/consulta_processo.php?nome_comarca=Tribunal+de + Justi\%E7a\&versao $=\&$ versao_fonetica $=1 \&$ tipo $=1 \&$ id_comarca $=700 \&$ num_processo_mask $=700$ $51349231 \&$ num_processo $=70051349231 \&$ codEmenta $=5044386 \&$ temIntTeor $=$ true. Acesso em: 12 ago. 2016.

. Tribunal de Justiça. Apelação Cível n. 70004003745. Des Rel. Ana Maria Nedel Scalzilli. Quinta Câmara Cível. Julgado em: 26/06/2003. Disponível em:http://www.tjrs.jus.br/busca/search?q=cache:www1.tjrs.jus.br/site_php/consulta/consulta_proc esso.php\%3Fnome_comarca\%3DTribunal\%2Bde\%2BJusti\%25E7a\%26versao\%3D\%26versao_fo netica\%3D1\%26tipo\%3D1\%26id_comarca\%3D700\%26num_processo_mask\%3D70004003745 \%26num_processo\%3D70004003745\%26codEmenta\%3D652831+70004003745++++\&proxystyl esheet $=\mathrm{tjrs} \_$index $\&$ client $=\mathrm{tjrs} \_$index $\& \mathrm{ie}=\mathrm{UTF}-$

$8 \& 1 \mathrm{l}=$ lang_pt\&site $=$ ementario $\&$ access $=$ p\&oe $=U T F-$

8\&numProcesso=70004003745\&comarca=CAXIAS\%20DO $\% 20$ SUL\&dtJulg=26/06/2003\&relat or=Ana\%20Maria\%20Nedel\%20Scalzilli\&aba=juris. Acesso em: 10 jul. 2016.

Tribunal de Justiça. Apelação Cível n. 70036483592. Des Rel. Iris Helena Medeiros Nogueira. Nona Câmara Cível. Julgado em: 29/01/2012. Disponível em: http://www.tjrs.jus.br/busca/search?q=cache:www1.tjrs.jus.br/site_php/consulta/consulta_process o.php\%3Fnome_comarca\%3DTribunal\%2Bde\%2BJusti\%25E7a\%26versao\%3D\%26versao_fonet ica\%3D1\%26tipo\%3D1\%26id_comarca\%3D700\%26num_processo_mask\%3D70036483592\%26 num_processo\%3D70036483592\%26codEmenta\%3D4563836+70036483592++++\&proxystylesh eet $=$ tjrs_index\&client $=$ tjrs_index $\&$ ie $=U T F-8 \& l r=l a n g \_p t \& s i t e=$ ementario $\&$ access $=p \& o e=U T F-$ $8 \&$ numProcesso $=70036483592 \&$ comarca $=$ Comarca $\% 20$ de $\% 20$ Porto $\% 20$ Alegre $\& d t J u l g=20 / 01 / 2$ 012\&relator=Iris\%20Helena\%20Medeiros\%20Nogueira\&aba=juris. Acesso em: 20 jul. 2016.

. Tribunal de Justiça. Apelação Cível n. 70011022589. Des Rel. Marilene Bonzanini. Nona Câmara Cível. Julgado em: 20/04/2005. Disponível em:http://www.tjrs.jus.br/busca/search?q=cache:www1.tjrs.jus.br/site_php/consulta/consulta_proc esso.php\%3Fnome_comarca\%3DTribunal\%2Bde\%2BJusti\%25E7a\%26versao\%3D\%26versao_fo netica\%3D1\%26tipo\%3D1\%26id_comarca\%3D700\%26num_processo_mask\%3D70011022589 \%26num_processo\%3D70011022589\%26codEmenta\%3D1070796+70011022589++++\&proxyst ylesheet $=$ tjrs_index \&client $=$ tjrs_index $\&$ ie $=U T F-$

$8 \& \mathrm{lr}=$ lang_pt\&site $=$ ementario\&access $=$ p\&oe $=U \mathrm{UTF}-$

$8 \&$ numProcesso $=70011022589 \&$ comarca $=$ Comarca $\% 20 \mathrm{de} \% 20$ Porto $\% 20$ Alegre $\& \mathrm{dtJulg}=20 / 04 / 2$ 005\&relator=Marilene\%20Bonzanini\&aba=juris. Acesso em: 27 jul. 2016.

TARTUCE, Flávio. NEVES, Daniel Amorim Assumpção. Manual de Direito do Consumidor: Direito material e processual - 5. ed. rev. atual. e ampl. - Rio de Janeiro: Forense: São Paulo: Método, 2016. 